\title{
Determination of Atorvastatin with Voltammetric Sensors Based on Nanomaterials
}

\author{
Ramona Oana Gunache (Roșca), Alexandra Virginia Bounegru (D) and Constantin Apetrei *(D)
}

Citation: Gunache (Roșca), R.O.;

Bounegru, A.V.; Apetrei, C.

Determination of Atorvastatin with

Voltammetric Sensors Based on

Nanomaterials. Inventions 2021, 6, 57.

https://doi.org/10.3390/

inventions6030057

Academic Editors: Eugen Rusu and Gabriela Rapeanu

Received: 20 July 2021

Accepted: 11 August 2021

Published: 12 August 2021

Publisher's Note: MDPI stays neutral with regard to jurisdictional claims in published maps and institutional affiliations.

Copyright: (c) 2021 by the authors. Licensee MDPI, Basel, Switzerland. This article is an open access article distributed under the terms and conditions of the Creative Commons Attribution (CC BY) license (https:// creativecommons.org/licenses/by/ $4.0 /)$.
Department of Chemistry, Physics and Environment, Faculty of Sciences and Environment, “Dunarea de Jos" University of Galati, 47 Domneasca Street, 800008 Galati, Romania; oana.gunache@ugal.ro (R.O.G.); alexandra.meresescu@ugal.ro (A.V.B.)

* Correspondence: apetreic@ugal.ro; Tel.: +40-727-580-914

\begin{abstract}
This paper presents an accurate and fast electrochemical method for atorvastatin determination in pharmaceutical products. Two screen-printed sensors, one-carbon based (SPCE) and one based on carbon nanotubes and gold nanoparticles (AuNP-CNT/SPCE) were used during the electrochemical analyses. At all experimental stages, cyclic voltammetry was employed, both for the characterization of the sensors and their electrochemical behavior, and for quantitative determinations. AuNP-CNT/SPCE has showed an extended active area, higher intensity peaks, better reversibility and lower background current than the unmodified sensor. For atorvastatin quantification, a calibration curve has been developed within the $1.2-606.25 \mu \mathrm{M}$ concentration range. A linearity relation between the current of the anodic peak and concentration has been obtained in the range 1.2-53.33 $\mu \mathrm{M}$ for both sensors. With the AuNP-CNT/SPCE sensor, low values of limit of detection, LOD $\left(1.92 \times 10^{-7} \mathrm{M}\right)$ and limit of quantification, LOQ $\left(6.39 \times 10^{-7} \mathrm{M}\right)$ have been obtained, which demonstrates the feasibility of the method of determining atorvastatin from real samples. Atorvastatin amount has been successfully determined from pharmaceutical products using AuNP-CNT/SPCE. The results were similar to the manufacturer's specifications regarding the dosage per tablet and to the concentrations obtained by applying the FTIR spectrometric method.
\end{abstract}

Keywords: atorvastatin; sensor; cyclic voltammetry; carbon nanotubes; gold nanoparticles

\section{Introduction}

Hyperlipidemia is a chronic condition manifested through the increase of the triglyceride levels in blood. The most effective and widely used medication for the treatment of hyperlipidemia is statins. Atorvastatin falls in this category, being an inhibitor of HMG-CoA reductase (an enzyme indispensable for cholesterol biosynthesis in liver) with significant anti-hypercholesterolemic effects [1]. Structurally, atorvastatin is an aromatic amide, a monofluorobenzene derivative, a dihydroxy monocarboxylic acid and a pyrrole derivative. Atorvastatin is also a derivative of heptanoic acid [2] (Scheme 1).<smiles>CC(C)c1c(C(=O)Nc2ccccc2)c(-c2ccccc2)c(-c2ccc(F)cc2)n1CC[C@@H](O)C[C@@H](O)CC(=O)O</smiles>

Scheme 1. Chemical structure of atorvastatin. 
This compound reduces the cholesterol quantity in blood, lowering the risk of cardiovascular diseases and cerebrovascular accidents. It is generally administered in the form of atorvastatin calcium trihydrate, in doses of 10 to $80 \mathrm{mg}$ per day. As any drug, atorvastatin may have some side effects, such as muscular or hepatic problems or increased glycemia [3]. Consequently, monitoring the atorvastatin concentration in pharmaceutical formulation may have an extremely significant role in adjusting the administered dose [4].

Up until now, researchers have applied more techniques for the analytical determination of atorvastatin both in drugs and biological samples, such as: liquid chromatography $[5,6]$, high performance liquid chromatography $[7,8]$, spectrophotometry $[9,10]$, but also electrochemical techniques [11-13]. Even though the chromatographic and spectrophotometric methods provide precise results, they require using expensive instruments and devices, and additional stages of sample pretreatment, which increase both the cost and time of the analysis. On the other hand, the electrochemical methods require the use of electrodes modified with various nanomaterials, which present multiple advantages, such as short response time, selectivity, sensitivity, precision and, above all, the possibility of miniaturizing [14-18].

Among nanomaterials, carbon nanotubes (CNT) are frequently used for the modification of screen-printed sensors, owing to their mechanical properties, remarkable electrical conductivity, optimal surface, high chemical resistance and stability [19,20].

In addition, in the last few years, metallic nanoparticles have drawn the scientific community's attention with their chemical and physical particularities, which make them suitable for electrochemical sensors modification [21,22]. Special attention was granted to gold nanoparticles (AuNP) because of their good biological compatibility, excellent conductibility and high surface-volume ratio. Modifying the sensor surface with AuNP has increased the value of electrochemical tests $[23,24]$. The combination of CNT with AuNP with a view to modifying the screen-printed sensors may positively influence the detection process, favoring the transfer of electrons and selectivity [25].

This study aims at evaluating the electrochemical behavior of two screen-printed sensors, the former, carbon-based (SPCE) and the latter, based on gold-particles modified carbon nanotubes (AuNP-CNT/SPCE) and the qualitative and quantitative determination of atorvastatin in a pharmaceutical product. The AuNP-CNT/SPCE is different as design, materials and detection technique comparing with other sensors reported in literature [26]. The electrochemical method applied for detection will be cyclic voltammetry. The quantitative results obtained with the AuNP-CNT/SPCE sensor using voltammetry will be subsequently compared with the ones obtained using the FTIR method.

The novelty of this study is the development of a novel electroanalytical method based on AuNP-CNT/SPCE sensor for the sensitive and accurate determination of atorvastatin in real samples.

\section{Materials and Methods}

\subsection{Reactives and Solutions}

All reactives have been used without additional purification, as they presented analytical purity. The studies on the characterization of electrodes and optimization of the experimental parameters were conducted in potassium chloride $10^{-1} \mathrm{M}$ and potassium ferrocyanide $10^{-3} \mathrm{M}$, the compounds having been purchased from Sigma-Aldrich (St. Louis, MO, USA). All solutions were prepared with MilliQ ultrapure water (resistivity 18.2 $\mathrm{M} \Omega \times \mathrm{cm}$ ) obtained from a Milli-Q Simplicity ${ }^{\circledR}$ water purification system. For the atorvastatin detection studies, real samples, purchased from local pharmacies, were used.

\subsection{Electrochemical Measurements}

All electrochemical determinations using cyclic voltammetry were conducted using an EG\&G potentiostat/galvanostat (Princeton Applied Research, Oak Ridge, TN, USA) controlled by a Windows-operated computer with an ECHEM software, used for characterizing the electrodes signals and for atorvastatin electroanalysis. A classical three-electrode 
system was employed. The working electrode is the carbon screen-printed electrode (SPCE) or the one modified with carbon nanotubes and gold particles (AuNP-CNT/SPCE) from Metrohm-Dropsens. The reference electrode was the silver/silver chloride electrode, and the counter electrode was a platinum wire. The working electrode unmodified and modified with nanomaterials have a surface of $0.1256 \mathrm{~cm}^{2}$. The electrochemical measurements are repeatable, the sensors could be used more than 100 measurements without losing their sensitivity. All potentials indicated in this study refer to the $\mathrm{Ag} / \mathrm{AgCl}$ reference electrode.

The electrochemical method employed in all experimental analyses was cyclic voltammetry. In this study, for the stabilization of the sensors' electrochemical signal, 6 successive cycles with a $0.1 \mathrm{~V} / \mathrm{s}$ scan rate were recorded using cyclic voltammetry. After that, 2 successive cycles at the same scan rate were also recorded, and the second cycle was saved and it is considered the stable signal of the sensor in the tested sample solution.

The FTIR spectra were obtained using a Bruker ALPHA FT-IR spectrometer (BrukerOptik $\mathrm{GmbH}$, Ettlingen, Germany) which uses the OPUS software (BrukekrOptik GmbH, Ettlingen, Germany) within the $4000-500 \mathrm{~cm}^{-1}$ range (32 scans, resolution $4 \mathrm{~cm}^{-1}$ ) in the attenuated total reflection (ATR) mode. Between measurements, the ATR ZnSe crystal was cleaned with ultrapure water and isopropanol. The spectra were recorded towards the air as background.

\subsection{Analysis of Phramaceutical Samples}

The sensors' applicability was studied by atorvastatin detection analysis in PRF (i.e., medical prescription withheld in the pharmacy) pharmaceutical products (Sortis $20 \mathrm{mg}$, Sortis $10 \mathrm{mg}$ ). Sortis is one of the medicaments known as statins, which act towards lipids (fats) regulation in the body, being used for lowering the concentrations of cholesterol and triglycerides in blood.

The stock solution of atorvastatin in the form of atorvastatin calcium was obtained from pharmaceutical product Sortis. Sortis $20 \mathrm{mg}$ is a filmed tablet whose core contains atorvastatin calcium trihydrate, alongside other excipients, such as lactose monohydrate (54.50 $\mathrm{mg} / \mathrm{cp})$ and benzoic acid $(0.00008 \mathrm{mg} / \mathrm{cp})$, calcium carbonate, microcrystalline cellulose, sodium croscarmellose, polysorbate 80 , hydroxypropyl cellulose, magnesium stearate.

For the preparation of the stock solution, more tablets of pharmaceutical product were triturated and dissolved in water. Prior to trituration, the coat on the tablet surface had been removed by rinsing with double distilled water. After ultrasonication, the respective mixture was filtered, and the effluent collected. Then, the water was evaporated, obtaining a solid powder, which was further characterized using FTIR spectrometry. The FTIR spectrum was similar to the one reported in the literature for atorvastatin calcium [23]. The required quantity was dissolved in $\mathrm{KCl}$ solution of $0.1 \mathrm{M}$ concentration, resulting a stock solution of atorvastatin with $6 \times 10^{-4} \mathrm{M}$ concentration. The solution was ultrasonicated using the Elma S10H Elmasonic device for dissolution and homogenization. The stock solution obtained was appropriately diluted and then introduced into the electrochemical cell and the three electrodes (working, reference and counter electrode) were connected.

In the validation studies tablets of Sortis $20 \mathrm{mg}$ and Sortis $10 \mathrm{mg}$ were used. The pharmaceutical samples were analyzed in triplicate.

\section{Results and Discussion}

\subsection{Study of the Electrochemical Behavior of Sensors in KCl Solution and Potassium Ferrocyanide/KCl Solution}

The purpose of the preliminary analyses was the evaluation of the electrochemical behavior of two screen-printed sensors, the former, screen-printed carbon electrode (SPCE) and the latter, based on carbon modified with carbon nanotubes and gold nanoparticles (AuNP-CNT/SPCE).

During the first stage of analyses, an electrochemically inactive $\mathrm{KCl} 0.1 \mathrm{M}$ was used with a view to evaluate the active surface of the sensors. The potential range was optimized, 
and the stable signal was obtained in the range from -0.4 to $+0.7 \mathrm{~V}$. No peaks were highlighted in the recorded cyclic voltammograms, which could have suggested a possible contamination of the sensor surface. The sensors present low background currents, which guarantees their suitability for further experiments.

In the next stage, the SPCE and AuNP-CNT/SPCE electrodes were immersed in a solution with electrochemical activity, obtained from potassium ferrocyanide $10^{-3} \mathrm{M}$ and $\mathrm{KCl} 10^{-1} \mathrm{M}$, with a view to analyzing the electrochemical behavior of the sensors. The cyclic voltammograms were recorded at a scan rate of $0.1 \mathrm{~V} / \mathrm{s}$, in the potential range between $-0.4 \mathrm{~V}$ and $+0.7 \mathrm{~V}$. This range was proven stable and optimal for potassium ferrocyanide $/ \mathrm{KCl}$ solution too, having been applied in other studies [27].

Figure 1 presents the cyclic voltammograms of the SPCE and AuNP-CNT/SPCE sensors in potassium ferrocyanide $10^{-3} \mathrm{M}-\mathrm{KCl}_{10} 10^{-1} \mathrm{M}$ solution recorded at a $0.1 \mathrm{~V} / \mathrm{s}$ scan rate.

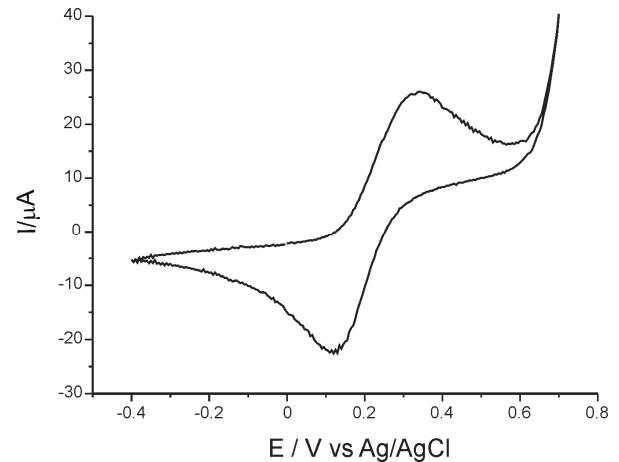

(a)

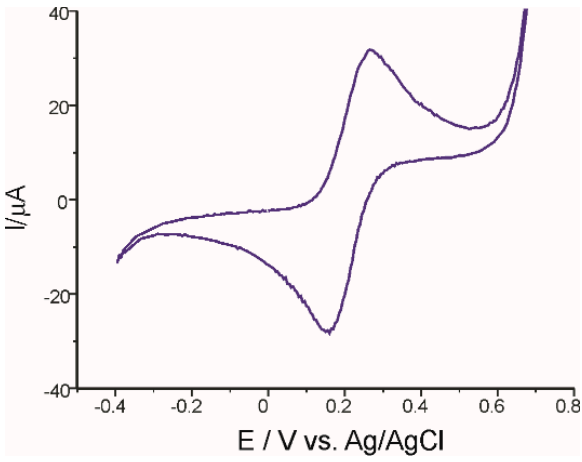

(b)

Figure 1. Cyclic voltammograms of the SPCE (a) and AuNP-CNT/SPCE (b) electrodes in $10^{-3} \mathrm{M}$ of $\mathrm{K}_{4}\left[\mathrm{Fe}(\mathrm{CN})_{6}\right]$ and $10^{-1} \mathrm{M} \mathrm{KCl}$ solution. Scan rate $0.1 \mathrm{~V} / \mathrm{s}$.

As seen in Figure 1, in both cases, the redox of the potassium ferrocyanide ion which takes place at the sensor surface is obvious, being observed an anodic and a cathodic peak.

The parameters of interest obtained, and the ones calculated following the voltammetric analysis are presented in Table 1.

Table 1. Electrochemical parameters obtained from cyclic voltammograms of the sensors immersed in $\mathrm{K}_{4}\left[\mathrm{Fe}(\mathrm{CN})_{6}\right] 10^{-3} \mathrm{M}$ $\mathrm{KCl} 10^{-1} \mathrm{M}$ solution.

\begin{tabular}{cccccccc}
\hline Sensor & $\mathbf{E}_{\mathbf{p a}}(\mathbf{V})$ & $\mathbf{E}_{\mathbf{p c}}(\mathbf{V})$ & $\mathbf{E}^{\mathbf{1 / 2}}(\mathbf{V})$ & $\mathbf{E}(\mathbf{V})$ & $\mathbf{I}_{\mathbf{a}}(\boldsymbol{\mu} \mathbf{A})$ & $\mathbf{I}_{\mathbf{c}}(\boldsymbol{\mu} \mathbf{A})$ & $\mathbf{I}_{\mathbf{c}} / \mathbf{I}_{\mathbf{a}}$ \\
\hline SPCE & 0.334 & 0.118 & 0.226 & 0.216 & 25.95 & -21.94 & 0.84 \\
AuNP-CNT/SPCE & 0.272 & 0.156 & 0.214 & 0.116 & 31.31 & -28.02 & 0.89 \\
\hline
\end{tabular}

Abbreviations: $\mathrm{E}_{\mathrm{pa}}$ - potential of the anodic peak; $\mathrm{E}_{\mathrm{pc}}$-potential of the cathodic peak; $\mathrm{I}_{\mathrm{a}}$-current of the anodic peak; $\mathrm{I}_{\mathrm{c}}$-current of the cathodic peak; $\mathrm{E}^{1 / 2}$-half wave potential, $\mathrm{E}=\mathrm{E}_{\mathrm{pa}}-\mathrm{E}_{\mathrm{pc}}$.

In the case of AuNP-CNT/SPCE, the peaks are better defined, of higher intensity and better reversibility ( $\mathrm{E}$ and $\mathrm{E}^{1 / 2}$ have lower values). By assessing the values of the principal parameters in the table, one can contend that the redox process of the ferrocyanide ion is quasi-irreversible in both cases, and that the sensors present good sensitivity.

In order to calculate the active area of the sensors, the cyclic voltammograms have been recorded in $10^{-3} \mathrm{M}$ potassium ferrocyanide- $-10^{-1} \mathrm{M}$ potassium chloride solution at various scan rates between the 0.05 and $1.0 \mathrm{~V} / \mathrm{s}$. The results obtained in the case of AuNP-CNT/SPCE are displayed in Figure 2. 


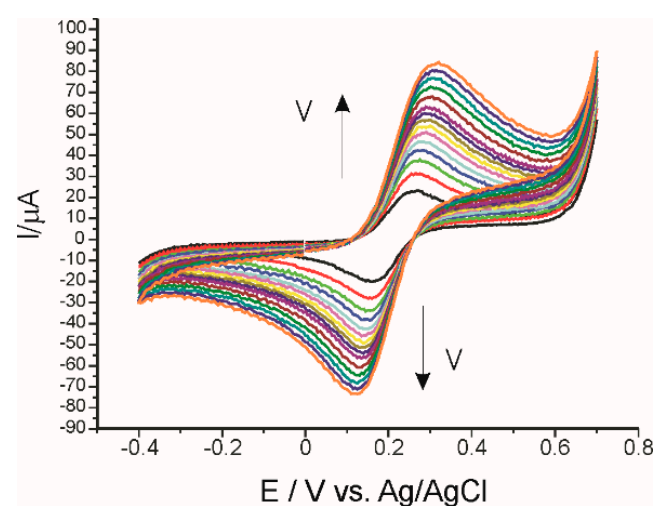

(a)

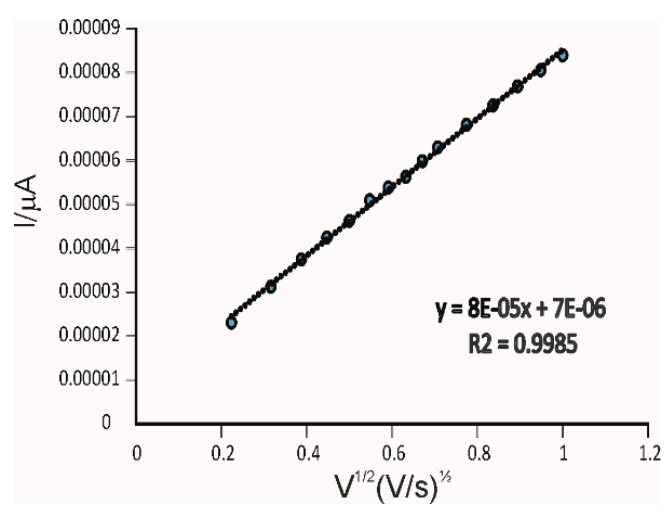

(b)

Figure 2. (a) Cyclic voltammograms of the AuNP-CNT/SPCE electrode in solution $10^{-3} \mathrm{M} \mathrm{K}_{4}\left[\mathrm{Fe}(\mathrm{CN})_{6}\right]-10^{-1} \mathrm{M} \mathrm{KCl}$ at various scan rates $(0.05-1.0 \mathrm{~V} / \mathrm{s})(\mathbf{b})$ Dependence $\mathrm{I}_{\mathrm{pa}}$ vs. square root of the scan rate.

After recording the cyclic voltammograms, one notes that the intensity of currents corresponding to the redox process of potassium ferrocyanide increases with the scan rate. By developing the linear regression between the intensity of the anodic current and scan rate, respectively, square root of the scan rate, one can determine the stage determining the rate of the oxidation process.

Figure $2 \mathrm{~b}$ shows good linearity between $\mathrm{I}_{\mathrm{pa}}$ and square root of the scan rate, with a determination coefficient $\left(\mathrm{R}^{2}\right)$ of 0.9985 . This result demonstrates that the electrochemical process at the level of the working electrode is controlled by the diffusion of the electroactive species, which concords with the literature [28]. The same type of linearity was also obtained by SPCE.

The active area of the electrodes was calculated by using the linear dependences between $\mathrm{I}_{\mathrm{pa}}$ and $\mathrm{v}^{1 / 2}$ and applying the Randles-Sevcik equation $[27,29]$.

$$
\mathrm{I}_{\mathrm{pa}}=268,600 \times \mathrm{n}^{3 / 2} \times \mathrm{A} \times \mathrm{D}^{1 / 2} \times \mathrm{Cv}^{1 / 2}
$$

where: $\mathrm{I}_{\mathrm{pa}}=$ current of the anodic peak $(\mathrm{A}) ; \mathrm{n}=$ number of electrons transferred in the redox process; $\mathrm{A}=$ electrode area $\left(\mathrm{cm}^{2}\right) ; \mathrm{D}=$ diffusion coefficient $\left(\mathrm{cm}^{2} / \mathrm{s}\right) ; \mathrm{C}=$ concentration $\left(\mathrm{mol} / \mathrm{cm}^{3}\right)$; $\mathrm{v}=$ scan rate $(\mathrm{V} / \mathrm{s})$.

The diffusion coefficient of the ferrocyanide ion is considered known: $\mathrm{D}=7.26 \times 10^{-6} \mathrm{~cm}^{2}$ $\times \mathrm{s}^{-1}[27]$.

Table 2 presents the values obtained for the area of active surface and the roughness factor of the two working electrodes.

Table 2. Geometric area, active surface area and roughness factor for SPCE and AuNP-CNT/SPCE.

\begin{tabular}{cccc}
\hline Electrode & Geometric Area $\left(\mathbf{c m}^{\mathbf{2}}\right)$ & Active Area $\left(\mathbf{c m}^{\mathbf{2}}\right)$ & Roughness Factor \\
\hline SPCE & 0.1256 & 0.2836 & 2.25 \\
AuNP-CNT/SPCE & & 0.9842 & 7.84 \\
\hline
\end{tabular}

AuNP-CNT/SPCE displays an active surface approximately 8 times larger than its geometric area and approx. 4 times larger than the active surface of the SPCE. The high sensitivity of the AuNP-CNT/SPCE modified sensor can be explained by the presence of the carbon nanotubes and gold particles which, owing to their shape, size and structure, present good electrical and mechanical properties, favoring the fast transfer of electrons [30,31], necessary in the case of electrochemical sensors. In addition, the association of carbon nanotubes and gold nanoparticles results in good conductibility and electrocatalytic capacity, thus increasing the sensor's selectivity, sensitivity and reproducibility [32,33]. 


\subsection{Study of the Electrochemical Behavior of the Sensors in Atorvastatin Solition (Support Electrolyte Solution $\mathrm{KCl} 10^{-1} \mathrm{M}$ )}

During the following stage, the response of the sensors in an atorvastatin solution of $3 \times 10^{-5} \mathrm{M}$ and $\mathrm{KCl} 10^{-1} \mathrm{M}$ was analyzed. The purpose of the analysis is to investigate the oxidation-reduction process of atorvastatin, using the sensors selected for this study. Furthermore, using cyclic voltammetry the sensitivity and selectivity of the sensors for the detection of atorvastatin were studied.

For stabilizing the sensors' responses, 6 cycles in the potential range between $-0.4 \mathrm{~V}$ and $+1.3 \mathrm{~V}$ were necessary. The results presented were obtained after the stabilization of the voltammetric signal.

Figure 3 presents the cyclic voltammograms of the sensors in atorvastatin $3 \times 10^{-5} \mathrm{M}$ solution (electrolyte $\mathrm{KCl} 10^{-1} \mathrm{M}$ solution).

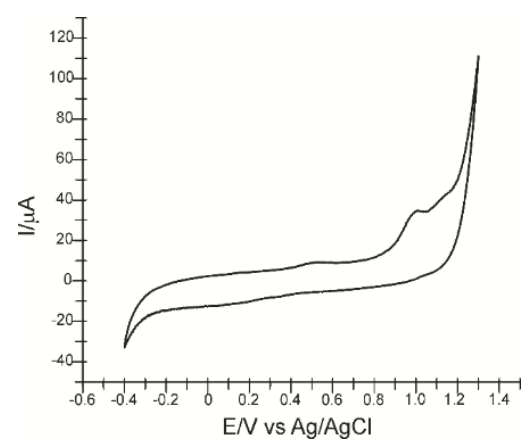

(a)

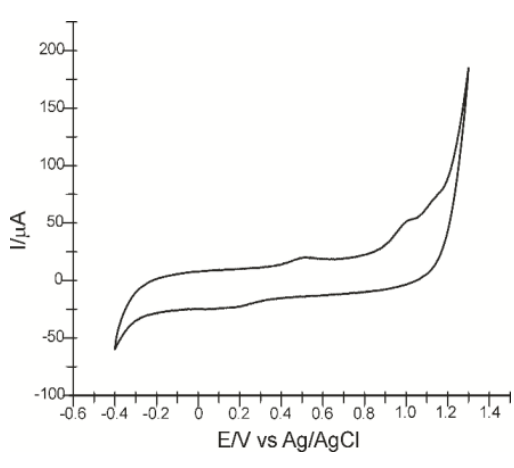

(b)

Figure 3. Cyclic voltammograms of the sensors: (a) SPCE and (b) AuNP-CNT/SPCE in atorvastatin $3 \times 10^{-5} \mathrm{M}$ solution. Scan rate $0.1 \mathrm{~V} / \mathrm{s}$.

Using both electrodes, one notes similar electrochemical behavior. The recorded cyclic voltammograms highlight two anodic and one cathodic peaks. The second anodic peak $\left(\mathrm{E}_{\mathrm{pa}}=1.004 \mathrm{~V}, \mathrm{I}_{\mathrm{pa}}=34.208 \mu \mathrm{A}\right.$ for SPCE and $\mathrm{E}_{\mathrm{pa}}=1.004 \mathrm{~V}, \mathrm{I}_{\mathrm{pa}}=51.82 \mu \mathrm{A}$ for AuNPCNT/SPCE) is related to the oxidation process of atorvastatin. The oxidation process is irreversible, as no cathodic peak associated to the oxidation of atorvastatin is observed.

In the initial phase of the oxidation process, atorvastatin loses one electron to form a cationic radical, which, in the following stage, loses one proton and one electron, a quaternary Schiff base being form. The resulting quaternary Schiff base suffers a rapid hydrolysis, two compounds appearing: the 3,5-dihydroxi-7-oxo-heptanoic acid and the fenylamide of acid 5-(4-Fluorophenyl)-2-isopropyl-4-phenyl-1H-pyrrole-3-carboxylic. This mechanism has been suggested by many researchers $[10,31,32]$. The scheme of the oxidation process of atorvastatin is presented in Figure 4.

Therefore, the electrochemical process entails the transfer of two electrons and two protons concomitantly detected by the screen-printed sensors. This electrochemical behavior of atorvastatin obtained with screen-printed sensors is similar to the one reported in the literature $[10,33]$.

It is noted that the anodic peak related to the oxidation of atorvastatin occurs at the same potential (at a $0.1 \mathrm{~V} / \mathrm{s}$ scan rate) for both sensors, but the intensity of current is higher in the case of AuNP-CNT/SPCE. This difference is given by the modifications of the surface of the screen-printed sensor. It is known that carbon nanotubes have good mechanical, electrical and thermic properties [17] and their association with the gold nanoparticles facilitates, in the case of atorvastatin oxidation, a well-defined electrochemical response, with higher intensity and lower background current. 


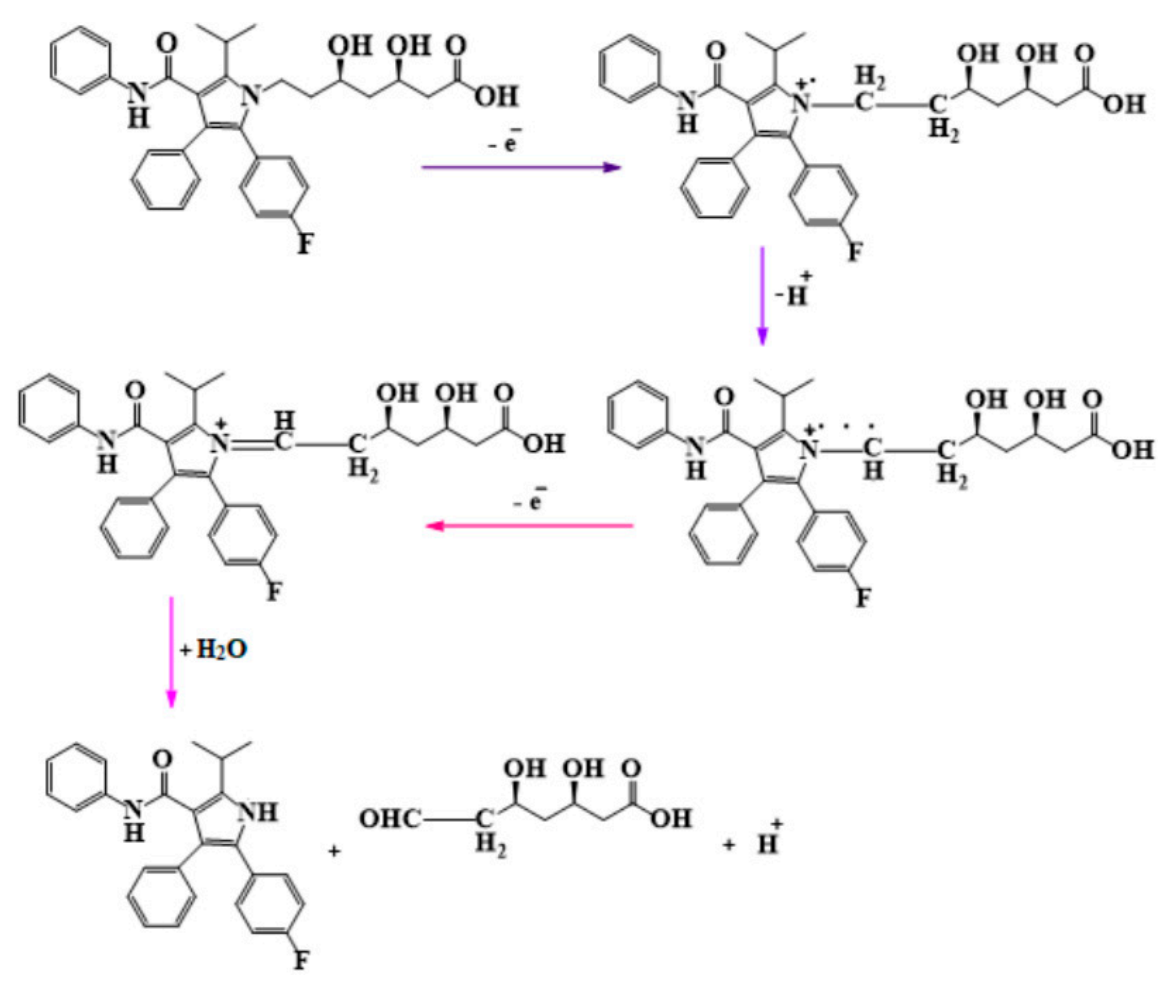

Figure 4. Mechanism proposed for electrochemical oxidation of atorvastatin. Adapted from [34].

According to the literature, rosuvastatin, for example, shows a slight oxidation at a different potential, usually with a higher value $(+1.26 \mathrm{~V})$ [35] $(+1.39 \mathrm{~V})$ [36], which is why, in a simultaneous detection analysis, the signals would not interfere and the selectivity of the sensor would prove to be optimal. More studies will be needed in this direction.

\subsection{Influence of the Scan Rate on the Sensors' Responses}

This section presents the scan rate's influence over the intensity and potential of the anodic peak corresponding to atorvastatin oxidation, using, in turn, SPCE and AuNPCNT/SPCE. Scan rates varied within a range from 0.1 and $1.0 \mathrm{~V} / \mathrm{s}$, modifying the scan rate gradually with $0.1 \mathrm{~V} / \mathrm{s}$ at each recording.

Applying gradual increases of scan rates the determining stage of the electrochemical process was achieved.

The intensity of the anodic peak increases, and the potential reaches higher values with the increase of the scan rate (Figure 5). This behavior is explained by the irreversible nature of the oxidation process, as confirmed by other studies [33]. The linear dependence of the anodic current to the scan rate and to the scan rate square root was also evaluated in order to determine whether the process is controlled by diffusion or adsorption.

Assessing the two linear dependences, one notes that the better linearity and a determination factor $\left(R^{2}\right)$ closer to 1 was obtained between the intensity of the anodic current and scan rate, as evident from Figure 6. This trend was observed for both sensors.

The linear regression equations for the anodic current intensity versus scan rate were as follows:

$$
\begin{gathered}
\operatorname{Ip}(\mu \mathrm{A})=132.16 \mathrm{v}(\mathrm{V} / \mathrm{s})+25.357, \mathrm{R}^{2}=0.9956(\text { for SPCE }) \\
\operatorname{Ip}(\mu \mathrm{A})=239.24 \mathrm{v}\left(\frac{\mathrm{V}}{\mathrm{s}}\right)+36.527, \mathrm{R}^{2}=0.995(\text { for AuNP }-\mathrm{CNT} / \mathrm{SPCE})
\end{gathered}
$$

In addition, the equations for the anodic current intensity logarithm versus the scan rate logarithm were also obtained:

$$
\log \operatorname{Ip}(\mu \mathrm{A})=0.6627 \log \mathrm{v}(\mathrm{V} / \mathrm{s})+2.1786, \mathrm{R}^{2}=0.9974(\text { for SPCE })
$$


$\log \operatorname{Ip}(\mu \mathrm{A})=0.7198 \log \mathrm{v}(\mathrm{V} / \mathrm{s})+2.4262, \mathrm{R}^{2}=0.9988($ for AuNP $-\mathrm{CNT} / \mathrm{SPCE})$

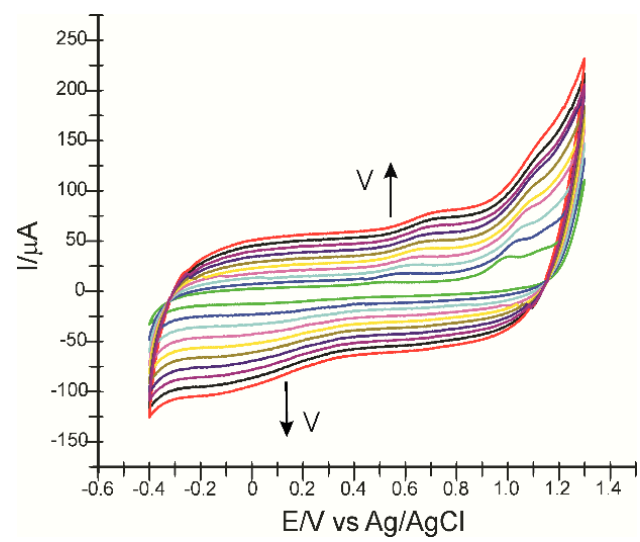

(a)

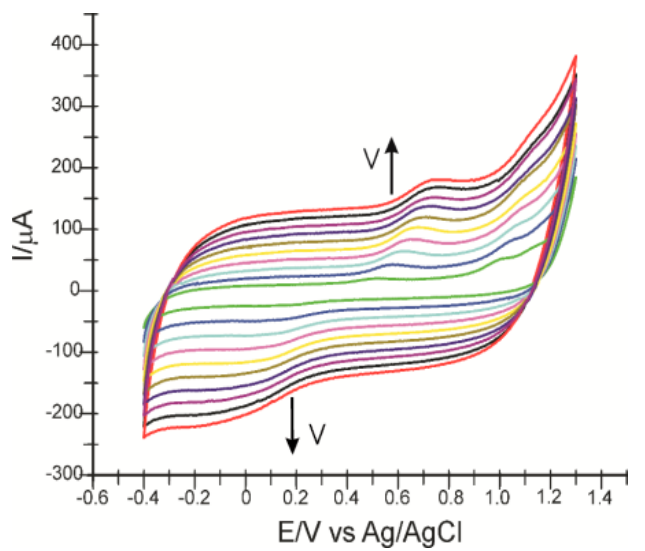

(b)

Figure 5. Cyclic voltammograms recorded by (a) SPCE and (b) AuNP-CNT/SPCE in atorvastatin $3 \times 10^{-5} \mathrm{M}$ solution (electrolyte $\mathrm{KCl} 10^{-1} \mathrm{M}$ solution) at scan rates ranging from $0.1 \mathrm{~V} / \mathrm{s}$ to $1.0 \mathrm{~V} / \mathrm{s}$.

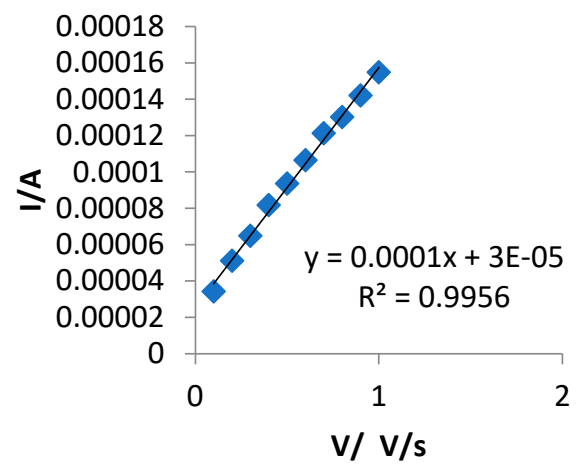

(a)

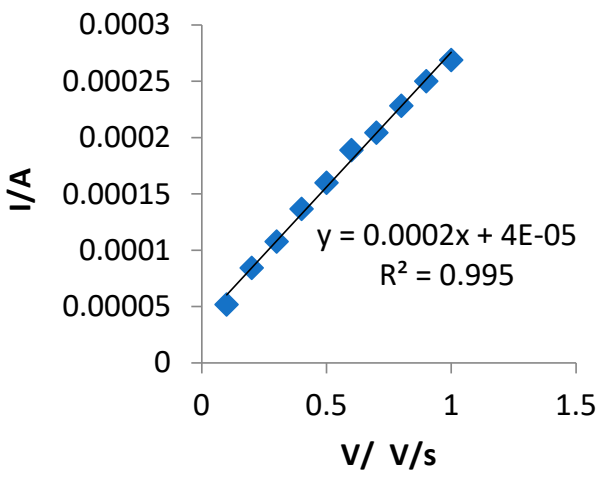

(b)

Figure 6. Linear dependence of the anodic current dependent on scan rate for (a) SPCE and (b) AuNP-CNT/SPCE.

The values of the slopes are close to the theoretical value (0.5) which corresponds to an ideal reaction of the species in solution [34]. Consequently, the oxidation mechanism of atorvastatin which takes place at the SPCE and AuNP-CNT/SPCE surface is an adsorptioncontrolled process [13,35].

However, the graphic between the anodic peak logarithm and the square root of scan rate logarithm shows a slope of 0.7589 and $\mathrm{R}^{2}=0.9973$ for SPCE, respectively, 0.6938 and $\mathrm{R}^{2}=0.9988$ for AuNP-CNT/SPCE, also indicating the presence of a diffusion process.

$$
\log \operatorname{Ip}(\mu \mathrm{A})=0.7525 \log \mathrm{v}^{1 / 2}(\mathrm{~V} / \mathrm{s})+1.64, \mathrm{R}^{2}=0.9973(\text { for SPCE})
$$

$\log \operatorname{Ip}(\mu \mathrm{A})=0.6938 \log \mathrm{v}^{\frac{1}{2}}\left(\frac{\mathrm{V}}{\mathrm{s}}\right)+1.6834, \mathrm{R}^{2}=0.9988($ for AuNP $-\mathrm{CNT} / \mathrm{SPCE})$

In order to investigate more thoroughly the atorvastatin electrochemical process which takes places at the electrodes surface, 5 cycles were recorded by cyclic voltammetry. The anodic peak current corresponding to atorvastatin displayed a significant decrease during the successive recordings (the results are not presented) in the first and the second scanning cycle, while the other three cycles remained almost unchanged, the signal being stable. These results confirm that the process that takes place at the surface is adsorption-controlled, 
but the diffusion process also plays an important role. Such electrochemical behavior of atorvastatin has also been reported in other studies [33].

In order to calculate the concentration of the electroactive species adsorbed on the active surface of the electrode, Laviron equation was employed [37].

$$
\mathrm{i}_{\mathrm{p}}=\frac{\mathrm{n}^{2} \mathrm{~F}^{2} \Gamma A v}{4 \mathrm{RT}}
$$

where: $\Gamma$-surface concentration of the electroactive species, $\mathrm{mol} \times \mathrm{cm}^{-2} ; \mathrm{i}_{\mathrm{p}}$-current corresponding to the peak, A; A-electrode supraface, $\mathrm{cm}^{2} ; \mathrm{n}$-number of electrons transferred during the redox processes; F-Faraday constant, $96,485 \mathrm{C} \times \mathrm{mol}^{-1}$; R-molar gas constant, $8.314 \mathrm{~J} / \mathrm{mol} \mathrm{K}$; T—absolute temperature, K; $298 \mathrm{~K}$.

According to the atorvastatin oxidation process, the number of transferred electrons is $2[10,33]$.

Table 3 displays the $\Gamma$ values obtained from Equation (2).

Table 3. Equation of the linear regression $\mathrm{I}_{\mathrm{p}} \mathrm{vs} . \mathrm{v}, \mathrm{R}^{2}$ and $\Gamma$ corresponding to the two sensors.

\begin{tabular}{cccc}
\hline Electrode & Equation & $\mathbf{R}^{\mathbf{2}}$ & $\left(\mathbf{m o l} \times \mathbf{c m}^{-\mathbf{2}}\right)$ \\
\hline SPCE & $\mathrm{I}_{\mathrm{p}}=1.32 \times 10^{-4} \mathrm{v}+2.53 \times 10^{-5}$ & 0.9956 & $1.11 \times 10^{-11}$ \\
AuNP-CNT/SPCE & $\mathrm{I}_{\mathrm{p}}=2.39 \times 10^{-4} \mathrm{v}+3.65 \times 10^{-5}$ & 0.9950 & $4.94 \times 10^{-10}$ \\
\hline
\end{tabular}

The values obtained for the degree of covering the surface with electroactive species conform with the values reported by other studies [33].

It can be asserted that AuNP-CNT/SPCE has superior electroanalytical properties in comparison with SPCE at atorvastatin detection. The presence of carbon nanotubes and gold nanoparticles ensures better conductibility and selectivity of the sensor in real samples.

\subsection{Calibration Curve and Detection Limit}

In optimized experimental conditions, the SPCE and AuNP-CNT/SPCE electrodes were used for the voltammetric determination of atorvastatin. A calibration curve was developed to determine the sensor response linearity range towards concentrations and to calculate the detection and quantification limit. The results are displayed in Figure 7. For the calibration curve, an atorvastation stock solution was used $\left(6 \times 10^{-4} \mathrm{M}\right)$, out of which clearly defined volumes were added to the electrolyte solution of $\mathrm{KCl}^{-1} \mathrm{M}$. The concentration range under focus was $1.2-606.25 \mu \mathrm{M}$. A good linearity was obtained in the $1.2-53.33 \mu \mathrm{M}$ range for both sensors, as shown in Figure 7.

With the help of the linear calibration curve equation and standard deviation, the values of detection limit $(\mathrm{LOD}=3 \sigma / \mathrm{m})$ and quantification $(\mathrm{LOQ}=10 \sigma / \mathrm{m})$ [38] were calculated (Table 4)

Table 4. The equations of linear fitting $\mathrm{I}_{\mathrm{pa}}$ vs. $\mathrm{c}, \mathrm{R}^{2}$, LOD and LOQ values for the two sensors for atorvastatin detection.

\begin{tabular}{ccccc}
\hline Sensor & Equation of the Linear Calibration Curve & $\mathbf{R}^{\mathbf{2}}$ & LOD $(\boldsymbol{\mu M})$ & LOQ $(\boldsymbol{\mu M})$ \\
\hline SPCE & $\mathrm{I}_{\mathrm{pa}}=0.0383 \mathrm{c}+2.2746$ & 0.9716 & $6.75 \times 10^{-7}$ & $2.25 \times 10^{-6}$ \\
AuNP-CNT/SPCE & $\mathrm{I}_{\mathrm{pa}}=0.0252 \mathrm{c}+10.762$ & 0.9892 & $1.92 \times 10^{-7}$ & $6.39 \times 10^{-7}$ \\
\hline
\end{tabular}



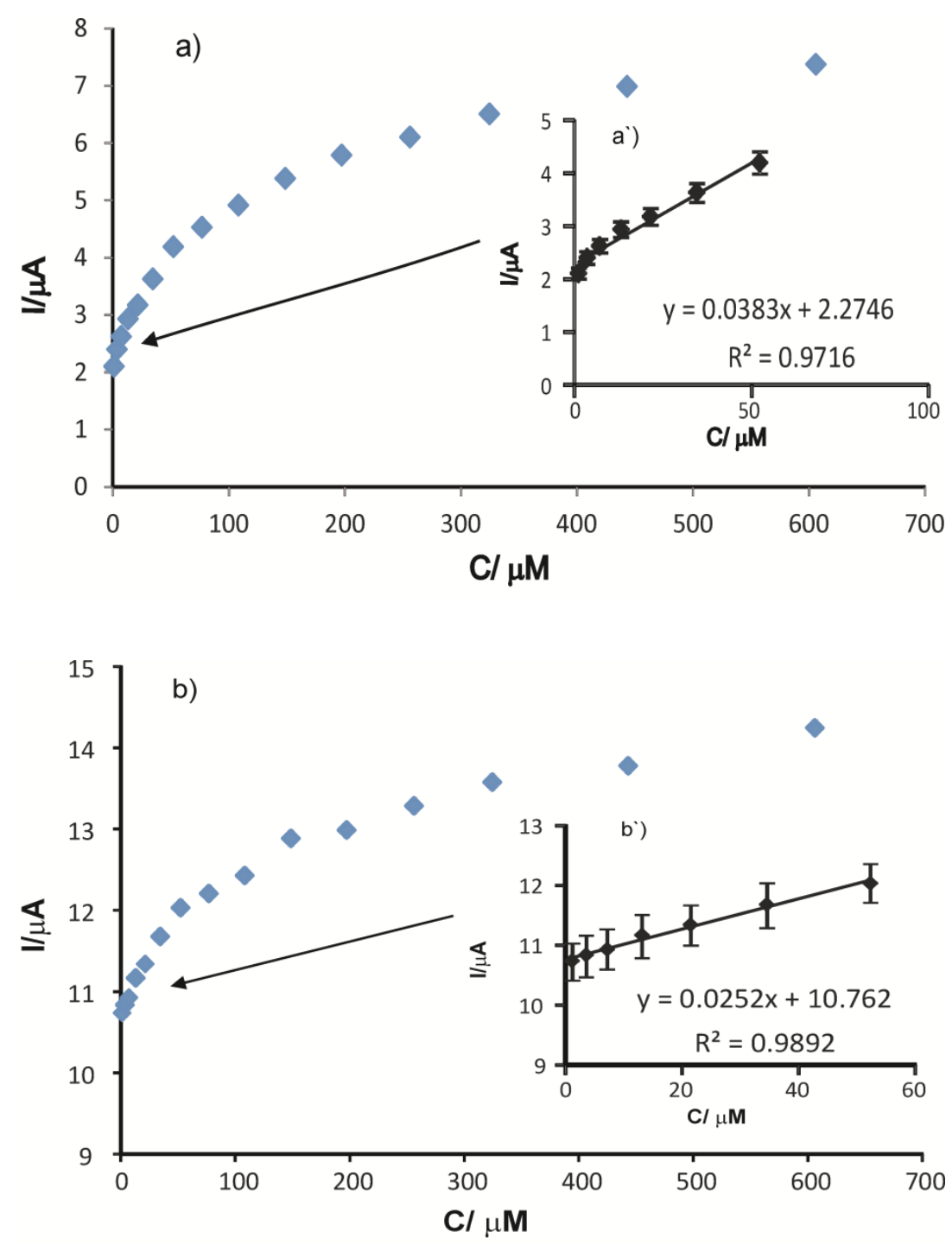

Figure 7. The linear fitting between $I_{p a}$ and the atorvastatin concentration for (a) SPCE and (b) AuNP-CNT/SPCE in the 1.2-606.25 $\mu \mathrm{M}$ concentration range. The inserted figures present the linear dependence between $\mathrm{I}_{\mathrm{pa}}$ and $\mathrm{c}$ for $\left(\mathrm{a}^{\prime}\right)$ SPCE and ( $\left.\mathrm{b}^{\prime}\right)$ AuNP-CNT/SPCE in the 1.2-53.33 $\mu \mathrm{M}$ concentration range. Error bars are represented for a standard error of $5 \%$.

SPCE/CNT-AuNP presents low LOD and LOQ values, which indicates high sensitivity. Consequently, the voltammetric method is precise and feasible for qualitative and quantitative atorvastatin determination. The values obtained are even below the ones reported in the literature (Table 5), which proves that SPCE/CNT-AuNP has very good electroanalytical performance for atorvastatin detection.

This study has emphasized the excellent electrochemical properties of the SPCE/CNTAuNP sensor, which are the result of the association of carbon nanotubes and gold nanoparticles. These superior properties have been marked out through an extended area of active surface and low detection limit and quantification values. Therefore, AuNP-CNT/SPCE has been used for the determination of atorvastatin in real samples. 
Table 5. Sensitive materials, detection technique, linear range and LOD of some sensors used for the detection of atorvastatin.

\begin{tabular}{|c|c|c|c|c|c|}
\hline Sensitive Materials & Detection Technique & Linear Range $(\mu \mathrm{M})$ & LOD $(\mu \mathrm{M})$ & Real Sample & Ref. \\
\hline PbTe NPs $/$ SPE $^{1}$ & cronAmp & $1-70$ & 0.05 & Tablet urine & [34] \\
\hline $\mathrm{GCE}^{2}$ & $\begin{array}{l}\text { DPV } \\
\text { SWV }\end{array}$ & $1-50$ & $\begin{array}{l}0.2 \\
0-3\end{array}$ & Tablet & [12] \\
\hline $\mathrm{Fe}_{3} \mathrm{O}_{4} @ \mathrm{PPy} / \mathrm{MWCNTs} / \mathrm{GE}^{3}$ & SWASV & 0.0314-201 & 0.0230 & Tablet and human serum & [38] \\
\hline $\mathrm{AgNWs} / \mathrm{Au} / \mathrm{GCE}^{4}$ & $\begin{array}{l}\text { CV } \\
\text { DPV }\end{array}$ & $10 \times 10^{-6}-1 \times 10^{-3}$ & $1 \times 10^{-3}$ & Tablet & [14] \\
\hline EPPGE $^{5}$ & $\begin{array}{l}\text { DPV } \\
\text { SWV }\end{array}$ & $\begin{array}{l}0.0960-5.60 \\
0.0960-7.74\end{array}$ & $\begin{array}{l}21.0 \\
23.0\end{array}$ & Tablet & [13] \\
\hline $\mathrm{PPY} / \mathrm{CNTs} / \mathrm{GCE}^{6}$ & LSV & $0.005-1.0$ & 0.0015 & Tablet & [39] \\
\hline $\mathrm{ZnO} / \mathrm{NS} / \mathrm{CPE}^{7}$ & $\begin{array}{l}\text { DPV } \\
\text { SWV }\end{array}$ & $\begin{array}{c}1.00-12.0 \\
0.01-0.1\end{array}$ & $\begin{array}{c}7 \times 10^{-4} \\
1.2 \times 10^{-4}\end{array}$ & Tablet and urine & [11] \\
\hline PPY-GNs/GCE ${ }^{8}$ & DPV & $20.0-200$ & 1.20 & Tablet & [40] \\
\hline VACNT-GO electrode ${ }^{9}$ & DPAdSV & $0.09-3.81$ & $9.4 \times 10^{-3}$ & Urine and human serum & [41] \\
\hline CPE in the presence of CTAB ${ }^{10}$ & DPV & $0.05-10$ & $4.08 \times 10^{-3}$ & Tablet and urine & [42] \\
\hline
\end{tabular}

${ }^{1}$ Lead telluride nanoparticles-modified graphite screen-printed electrodes; ${ }^{2}$ glassy carbon electrode; ${ }^{3}$ graphite electrode (GE) modified with polypyrrole-coated $\mathrm{Fe}_{3} \mathrm{O}_{4}$ nanohybrid by core-shell structure $\left(\mathrm{Fe}_{3} \mathrm{O}_{4} @\right.$ PPy NPs) and multiwall carbon nanotubes (MWCNTs); ${ }^{4}$ silver nanowires/gold-modified glassy carbon electrode; ${ }^{5}$ edge-plane pyrolytic graphite electrode; ${ }^{6}$ Polypyrrole/Carbon nanotube/Glassy carbon electrode; ${ }^{7}$ zinc oxide nanoparticles and nano-silica carbon paste electrode; ${ }^{8}$ polypyrrole functionalized graphene sheets/glassy carbon electrode; ${ }^{9}$ vertically aligned carbon nanotube/graphene oxide; ${ }^{10}$ carbon paste electrode (CPE) in the presence of an enhancing agent, cetyltrimethyl ammonium bromide (CTAB).

For this study, the real samples were pharmaceutical products in the form of tablets. As can be seen in the Table 5, many authors have determined atorvastatin from various types of biological samples. Biological samples involve several stages of pretreatment and storage [43], involving higher costs and a longer time. Moreover, the detection from biological samples implies the existence of interferences that can be difficult to control. Metabolites of other compounds in urine or plasma may significantly impair or alter the sensor signal. The future step of our research will be the detection of statins in biological samples.

\subsection{Atorvastatin Determination in the Pharmaceutical Products}

In the next experimental step, the aim is to demonstrate the sensitivity and accuracy of the AuNP-CNT/SPCE sensor for the qualitative and quantitative determination of the analyte of interest in a pharmaceutical products. For the determination of atorvastatin in the pharmaceutical products, AuNP-CNT/SPCE was used, applying cyclic voltammetry. The potential range was between $-0.4 \mathrm{~V}$ and +1.3 and the scan rate was of $0.1 \mathrm{~V} / \mathrm{s}$. The cyclic voltammogram points out the peak corresponding to the presence of atorvastatin in the pharmaceutical products. Taking into consideration the anodic peak intensity, the quantity of product analyzed and the linear calibration equation, the quantity of atorvastatin in the pharmaceutical products were calculated.

The results obtained conform to the values reported by manufacturers, which demonstrates the precision of the AuNP-CNT/SPCE sensor (Table 6).

Table 6. Atorvastatin concentrations in Sortis obtained by voltammetry and, respectively, by FTIR.

\begin{tabular}{|c|c|c|c|}
\hline Product & $\begin{array}{l}\text { Atorvastatin Quantity Reported } \\
\text { by the Manufacturer (mg/cp) }\end{array}$ & \multicolumn{2}{|c|}{ Atorvastatin Quantity Experimentally Determined } \\
\hline & & $\mathrm{CV}$ (mg/cp) method & FTIR (mg/cp) method \\
\hline Sortis $20 \mathrm{mg}$ & 20 & $20 \pm 1$ & $21 \pm 2$ \\
\hline Sortis $10 \mathrm{mg}$ & 10 & $10 \pm 0.5$ & $10.5 \pm 0.5$ \\
\hline
\end{tabular}

The voltammetric method was validated using the FTIR spectrometric method. The FTIR method presents a considerable potential in medicine quality control, as it is capable of identifying the chemical structure and the identity of the active substance in various samples. For this test, a solid standard of atorvastatin- $\mathrm{KBr}$ in $10 \mathrm{mg} / \mathrm{g}$ concentration was prepared, and the linear calibration curve was determined based on the absorbers of the peak at a wave length of $1316 \mathrm{~cm}^{-1}$, specific to the stretching vibration of the C-N group [44]. 
Figure 8 displays the FTIR spectrum of the sample obtained from the pharmaceutical product Sortis $20 \mathrm{mg}$.

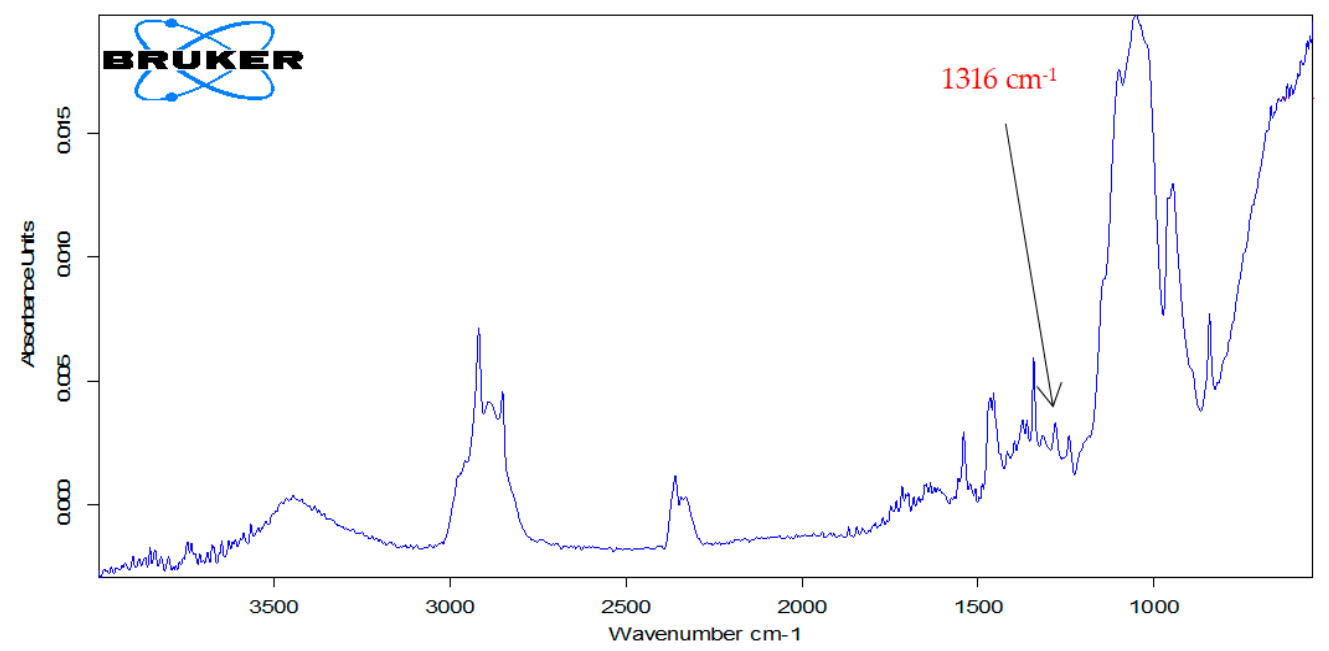

Figure 8. FTIR spectrum of Sortis $20 \mathrm{mg}$.

All samples were analyzed in triplicate. The results are outlined in Table 6.

It is noted that the values obtained are similar for both methods. In addition, the atorvastatin concentrations obtained in this study correspond to the concentration reported by manufacturer. These results demonstrate the accuracy and precision of the voltammetric method, as well as the sensitivity and selectivity of the AuNP-CNT/SPCE sensor.

\subsection{Recovery Test}

The analytical recovery was determined using cyclic voltammetry, after the addition of clearly determined quantities of pharmaceutical product solutions, more precisely, $3 \times 10^{-6}, 5 \times 10^{-6}$ and $7 \times 10^{-6} \mathrm{M}$.

Analytical recoveries ranged between 99.4 and 100.9\% (Table 7) at approx. 1\% RSD (relative standard deviation). The values of the analytical recovery obtained are related to the presence of some excipients, which may interfere with the electrochemical response. The results obtained are positive, and the sensor may be used in pharmaceutical practice.

Table 7. Recovery test at atorvastatin detection.

\begin{tabular}{ccc}
\hline Atorvastatin Concentration $\left(\times \mathbf{1 0}^{\mathbf{6}} \mathbf{M}\right)$ & Atorvastatin Quantity $\left(\times \mathbf{1 0 ^ { \mathbf { 6 } }} \mathbf{M}\right)$ & Recovery $(\mathbf{\%}) \pm \mathbf{R S D}(\boldsymbol{n}=\mathbf{5})$ \\
\hline 3 & 3.03 & $100.5 \pm 0.9$ \\
5 & 4.97 & $99.4 \pm 0.8$ \\
7 & 7.06 & $100.9 \pm 0.9$ \\
\hline
\end{tabular}

\section{Conclusions}

This study has characterized the SPCE and AuNP-CNT/SPCE sensors with the purpose of determining the atorvastatin in pharmaceutical products. AuNP-CNT/SPCE displayed superior electrochemical behavior in comparison with SPCE as early as during the preliminary experiments. With a wider active surface area, AuNP-CNT/SPCE has recorded more intense and better defined peaks in the atorvastatin solution, the process being mainly controlled by the adsorption of the species at the electrode surface. For the quantification of atorvastatin, a calibration curve was determined and the calculated LOD and LOQ values proved higher sensitivity for AuNP-CNT/SPCE. In the quantitative analysis, the atorvastatin concentrations obtained with AuNP-CNT/SPCE are very close to the ones obtained by spectrometry, and also to the values reported by manufacturer. It can be thus concluded that the method employed is simple, versatile, precise and entails 
low costs. In addition, AuNP-CNT/SPCE is suitable for the screening analysis of complex samples that contain atorvastatin.

The present study could be a first step towards the development of a sensitive, portable, single-use device for the detection of atorvastatin in biological samples. Such a device could be used at home or in the hospital for the benefit of the patient. By monitoring the level of atorvastatin in the blood, the dose administered daily can be adjusted, and thus, liver function would be protected. Furthermore, further research could address the simultaneous detection of several statins (rosuvastatin or simvastatin), results that could make important contributions to drug control.

Author Contributions: Conceptualization, C.A. and R.O.G.; methodology, C.A.; validation, R.O.G. and A.V.B.; formal analysis, R.O.G.; investigation, R.O.G. and A.V.B.; resources, C.A.; writingoriginal draft preparation, R.O.G. and A.V.B.; writing-review and editing, C.A.; supervision, C.A. All authors have read and agreed to the published version of the manuscript.

Funding: The contribution of author Ramona Oana Gunache (Roșca) was supported by the project entitled "Excelența academică valori antreprenoriale—sistem de burse pentru asigurarea oportunităților de formare dezvoltare a competentelor antreprenoriale ale doctoranzilor post doctoran-zilorANTREPRENORDOC", Contract number 36355/23.05.2019 POCU/380/6/13-SMIS code: 123847.

Institutional Review Board Statement: Not applicable.

Informed Consent Statement: Not applicable.

Data Availability Statement: The authors confirm that the data supporting the findings of this study are available within the article.

Acknowledgments: The results of this work have been presented to the 9th edition of the Scientific Conference organized by the Doctoral Schools of “Dunărea de Jos" University of Galati (SCDS-UDJG) http: / / www.cssd-udjg.ugal.ro/, accessed on 10 June 2021 that will be held on 10 and 11 June 2021, in Galati, Romania.

Conflicts of Interest: The authors declare no conflict of interest.

\section{References}

1. Tsoukas, M.A.; Mantzoros, C.S. Lipodystrophy Syndromes. In Endocrinology: Adult and Pediatric; Elsevier: New York, NY, USA, 2016; pp. 648-661.e5, ISBN 978-0-323-18907-1.

2. Atorvastatin (CHEBI:39548). Available online: https:// www.ebi.ac.uk/chebi/searchId.do?chebiId=CHEBI:39548 (accessed on 31 July 2021).

3. Ramkumar, S.; Raghunath, A.; Raghunath, S. Statin Therapy: Review of Safety and Potential Side Effects. Acta Cardiol. Sin. 2016, 32, 631-639. [CrossRef] [PubMed]

4. Sewright, K.A.; Clarkson, P.M.; Thompson, P.D. Statin Myopathy: Incidence, Risk Factors, and Pathophysiology. Curr. Atheroscler. Rep. 2007, 9, 389-396. [CrossRef]

5. Martins, A.F.; Frank, C.D.S.; Altissimo, J.; de Oliveira, J.A.; da Silva, D.S.; Reichert, J.F.; Souza, D.M. Determination of Statin Drugs in Hospital Effluent with Dispersive Liquid-Liquid Microextraction and Quantification by Liquid Chromatography. J. Environ. Sci. Health Part A 2017, 52, 939-945. [CrossRef] [PubMed]

6. Danafar, H.; Hamidi, M. Method Validation of Amlodipine and Atorvastatin by Liquid Chromatography-Mass Spectrometry (LC-MS) Method in Human Plasma. Cogent Med. 2016, 3, 1129790. [CrossRef]

7. Emhofer, L.; Himmelsbach, M.; Buchberger, W.; Klampfl, C.W. High-Performance Liquid Chromatography Drift-Tube IonMobility Quadrupole Time-of-Flight/Mass Spectrometry for the Identity Confirmation and Characterization of Metabolites from Three Statins (Lipid-Lowering Drugs) in the Model Plant Cress (Lepidium Sativum) after Uptake from Water. J. Chromatogr. A 2019, 1592, 122-132. [CrossRef]

8. Dastkhoon, M.; Ghaedi, M.; Asfaram, A.; Arabi, M.; Ostovan, A.; Goudarzi, A. Cu@SnS/SnO 2 Nanoparticles as Novel Sorbent for Dispersive Micro Solid Phase Extraction of Atorvastatin in Human Plasma and Urine Samples by High-Performance Liquid Chromatography with UV Detection: Application of Central Composite Design (CCD). Ultrason. Sonochem. 2017, 36, 42-49. [CrossRef]

9. Bioanalytical Method Development and Validation of Atorvastatin in Human Plasma by Using UV-Visibile SpectrophotometryProQuest. Available online: https://www.proquest.com/openview /ffa8b2baa35d2ac4fbec030eeda904e2/1?pq-origsite= gscholar\&cbl=54977 (accessed on 15 July 2021).

10. Yilmaz, B.; Kaban, S. UV and First Derivative Spectrophotometric Methods for the Estimation of Atorvastatin in Pharmaceutical Preparations. J. Adv. Pharm. Res. 2018, 2, 89-94. [CrossRef] 
11. Bukkitgar, S.D.; Shetti, N.P.; Kulkarni, R.M. Construction of Nanoparticles Composite Sensor for Atorvastatin and Its Determination in Pharmaceutical and Urine Samples. Sens. Actuators B Chem. 2018, 255, 1462-1470. [CrossRef]

12. Yilmaz, B.; Kaban, S. Electrochemical Behavior of Atorvastatin at Glassy Carbon Electrode and Its Direct Determination in Pharmaceutical Preparations by Square Wave and Differential Pulse Voltammetry. Indian J. Pharm. Sci. 2016, 78, 360-367. [CrossRef]

13. Fazlolahzadeh, O.; Rouhollahi, A.; Hadi, M. Electroanalytical Determination of Atorvastatin in Pharmaceutical Formulations Based on Edge-Plane Pyrolytic Graphite Electrode. Anal. Bioanal. Electrochem. 2016, 8, 566-577.

14. Naseri, A.; Hormozi-Nezhad, M.R.; Shahrokhian, S.; Asadian, E. Silver Nanowires Immobilized on Gold-Modified Glassy Carbon Electrode for Electrochemical Quantification of Atorvastatin. J. Electroanal. Chem. 2020, 876, 114540. [CrossRef]

15. Kumar, S.; Bukkitgar, S.D.; Singh, S.; Pratibha; Singh, V.; Reddy, K.R.; Shetti, N.P.; Venkata Reddy, C.; Sadhu, V.; Naveen, S. Electrochemical Sensors and Biosensors Based on Graphene Functionalized with Metal Oxide Nanostructures for Healthcare Applications. ChemistrySelect 2019, 4, 5322-5337. [CrossRef]

16. Dakshayini, B.S.; Reddy, K.R.; Mishra, A.; Shetti, N.P.; Malode, S.J.; Basu, S.; Naveen, S.; Raghu, A.V. Role of Conducting Polymer and Metal Oxide-Based Hybrids for Applications in Ampereometric Sensors and Biosensors. Microchem. J. 2019, 147, 7-24. [CrossRef]

17. Kuzin, Y.; Kappo, D.; Porfireva, A.; Shurpik, D.; Stoikov, I.; Evtugyn, G.; Hianik, T. Electrochemical DNA Sensor Based on Carbon Black-Poly(Neutral Red) Composite for Detection of Oxidative DNA Damage. Sensors 2018, 18, 3489. [CrossRef]

18. Shamgsumova, R.V.; Shurpik, D.N.; Evtugyn, V.G.; Stoikov, I.I.; Evtugyn, G.A. Electrochemical Determination of Malathion on an Acetylcholinesterase-Modified Glassy Carbon Electrode. Anal. Lett. 2018, 51, 1911-1926. [CrossRef]

19. Iijima, S. Helical Microtubules of Graphitic Carbon. Nature 1991, 354, 56-58. [CrossRef]

20. Apetrei, C.; Apetrei, I.M. Biosensor Based on Tyrosinase Immobilized on a Single-Walled Carbon Nanotube-Modified Glassy Carbon Electrode for Detection of Epinephrine. IJN 2013, 4391. [CrossRef] [PubMed]

21. Claussen, J.C.; Kumar, A.; Jaroch, D.B.; Khawaja, M.H.; Hibbard, A.B.; Porterfield, D.M.; Fisher, T.S. Nanostructuring Platinum Nanoparticles on Multilayered Graphene Petal Nanosheets for Electrochemical Biosensing. Adv. Funct. Mater. 2012, 22, 3399-3405. [CrossRef]

22. Apetrei, I.M.; Apetrei, C. A Modified Nanostructured Graphene-Gold Nanoparticle Carbon Screen-Printed Electrode for the Sensitive Voltammetric Detection of Rutin. Measurement 2018, 114, 37-43. [CrossRef]

23. Cheng, W.; Dong, S.; Wang, E. Gold Nanoparticles as Fine Tuners of Electrochemical Properties of the Electrode/Solution Interface. Langmuir 2002, 18, 9947-9952. [CrossRef]

24. Guo, S.; Wang, E. Synthesis and Electrochemical Applications of Gold Nanoparticles. Anal. Chim. Acta 2007, 598, 181-192. [CrossRef]

25. Alim, S.; Vejayan, J.; Yusoff, M.M.; Kafi, A.K.M. Recent Uses of Carbon Nanotubes \& Gold Nanoparticles in Electrochemistry with Application in Biosensing: A Review. Biosens. Bioelectron. 2018, 121, 125-136. [CrossRef]

26. Serafín, V.; Martínez-García, G.; Agüí, L.; Yáñez-Sedeño, P.; Pingarrón, J.M. Multiplexed Determination of Human Growth Hormone and Prolactin at a Label Free Electrochemical Immunosensor Using Dual Carbon Nanotube-Screen Printed Electrodes Modified with Gold and PEDOT Nanoparticles. Analyst 2014, 139, 4556-4563. [CrossRef] [PubMed]

27. Apetrei, I.M.; Apetrei, C. Voltammetric Determination of Melatonin Using a Graphene-Based Sensor in Pharmaceutical Products. Int. J. Nanomed. 2016, 11, 1859-1866. [CrossRef]

28. Bounegru, A.; Apetrei, C. Voltammetric Sensors Based on Nanomaterials for Detection of Caffeic Acid in Food Supplements. Chemosensors 2020, 8, 41. [CrossRef]

29. Bard, A.J.; Faulkner, L.R. Electrochemical Methods: Fundamentals and Applications, 2nd ed.; Wiley: New York, NY, USA, 2001; ISBN 978-0-471-04372-0.

30. Bounegru, A.V.; Apetrei, C. Carbonaceous Nanomaterials Employed in the Development of Electrochemical Sensors Based on Screen-Printing Technique-A Review. Catalysts 2020, 10, 680. [CrossRef]

31. García-Carmona, L.; Moreno-Guzmán, M.; Sierra, T.; González, M.C.; Escarpa, A. Filtered Carbon Nanotubes-Based Electrodes for Rapid Sensing and Monitoring of L-Tyrosine in Plasma and Whole Blood Samples. Sens. Actuators B Chem. 2018, 259, 762-767. [CrossRef]

32. Bounegru, A.V.; Apetrei, C. Voltamperometric Sensors and Biosensors Based on Carbon Nanomaterials Used for Detecting Caffeic Acid-A Review. IJMS 2020, 21, 9275. [CrossRef]

33. Bounegru, A.V.; Apetrei, C. Development of a Novel Electrochemical Biosensor Based on Carbon Nanofibers-Gold NanoparticlesTyrosinase for the Detection of Ferulic Acid in Cosmetics. Sensors 2020, 20, 6724. [CrossRef]

34. Pourtaheri, E.; Taher, M.A.; Ali, G.A.; Agarwal, S.; Gupta, V.K. Low-Cost and Highly Sensitive Sensor for Determining Atorvastatin Using PbTe Nanoparticles-Modified Graphite Screen-Printed Electrode. Int. J. Electrochem. Sci. 2019, 14, 9622-9632. [CrossRef]

35. Silva, T.A.; Zanin, H.; Vicentini, F.C.; Corat, E.J.; Fatibello-Filho, O. Electrochemical Determination of Rosuvastatin Calcium in Pharmaceutical and Human Body Fluid Samples Using a Composite of Vertically Aligned Carbon Nanotubes and Graphene Oxide as the Electrode Material. Sens. Actuators B Chem. 2015, 218, 51-59. [CrossRef]

36. Silva, T.A.; Pereira, G.F.; Fatibello-Filho, O.; Eguiluz, K.I.B.; Salazar-Banda, G.R. Square-Wave Voltammetric Determination of Rosuvastatin Calcium in Pharmaceutical and Biological Fluid Samples Using a Cathodically Pretreated Boron-Doped Diamond Electrode. Diam. Relat. Mater. 2015, 58, 103-109. [CrossRef] 
37. Apetrei, I.M.; Rodriguez-Mendez, M.L.; Apetrei, C.; de Saja, J.A. Fish Freshness Monitoring Using an E-Tongue Based on Polypyrrole Modified Screen-Printed Electrodes. IEEE Sens. J. 2013, 13, 2548-2554. [CrossRef]

38. Tavousi, A.; Ahmadi, E.; Mohammadi-Behzad, L.; Riahifar, V.; Maghemi, F. Sensitive Electrochemical Sensor Using PolypyrroleCoated $\mathrm{Fe}_{3} \mathrm{O}_{4}$ Core-Shell Nanoparticles/Multiwall Carbon Nanotubes Modified Graphite Electrode for Atorvastatin Analysis. Microchem. J. 2020, 158, 105159. [CrossRef]

39. Kamalzadeh, Z.; Shahrokhian, S. Electrochemical Determination of Atorvastatin on Nano-Scaled Polypyrrole Film. Bioelectrochemistry 2014, 98, 1-10. [CrossRef] [PubMed]

40. Wei, L. Electrochemical Sensor for Ultrasensitive Determination of Atorvastatin Based on Polypyrrole Functionalized Graphene Sheets. Int. J. Electrochem. Sci. 2018, 10173-10180. [CrossRef]

41. Silva, T.A.; Zanin, H.; Vicentini, F.C.; Corat, E.J.; Fatibello-Filho, O. Differential Pulse Adsorptive Stripping Voltammetric Determination of Nanomolar Levels of Atorvastatin Calcium in Pharmaceutical and Biological Samples Using a Vertically Aligned Carbon Nanotube/Graphene Oxide Electrode. Analyst 2014, 139, 2832. [CrossRef]

42. Abbar, J.C.; Nandibewoor, S.T. Voltammetric Oxidation and Determination of Atorvastatin Based on the Enhancement Effect of Cetyltrimethyl Ammonium Bromide at a Carbon Paste Electrode. Colloids Surf. B Biointerfaces 2013, 106, 158-164. [CrossRef] [PubMed]

43. Eskiköy, D.; Durmuş, Z.; Kiliç, E. Electrochemical Oxidation of Atorvastatin and Its Adsorptive Stripping Determination in Pharmaceutical Dosage Forms and Biological Fluids. Collect. Czech. Chem. Commun. 2011, 76, 1633-1649. [CrossRef]

44. Shahraeini, S.S.; Akbari, J.; Saeedi, M.; Morteza-Semnani, K.; Abootorabi, S.; Dehghanpoor, M.; Rostamkalaei, S.S.; Nokhodchi, A. Atorvastatin Solid Lipid Nanoparticles as a Promising Approach for Dermal Delivery and an Anti-Inflammatory Agent. AAPS PharmSciTech 2020, 21, 263. [CrossRef] 